\author{
ENCARNACIÓN GIL-MESEGUER ${ }^{a}$ \\ MIGUEL BORJA BERNABÉ-CRESPO ${ }^{\mathrm{b}}$ \\ JOSÉ Ma GÓMEZ-ESPÍNc
}

\title{
RESILIENCIA EN EL CONSUMO DE AGUA POR PARTE DE ABASTECIMIENTOS Y REGADÍOS ANTE LAS SEQUÍAS EN EL SURESTE DE ESPAÑA
}

\begin{abstract}
RESUMEN
El objeto de estudio es analizar y comparar cómo responden regantes y abastecimientos a situaciones de sequía en el Sureste de España en el siglo XXI, con el ejemplo de las sequías de 2005-2008 y 2017-2018. Metodológicamente es un estudio de geografía regional con análisis cualitativo y cuantitativo, diacrónico y comparado, además del trabajo de campo. Entre las fuentes utilizadas destacan la consulta de archivos históricos, los datos de AEMET, los consumos de agua en abastecimientos y regadíos, y las entrevistas a gestores y usuarios. La respuesta ante las sequías del siglo XXI ha sido dispar. En la de 2005-2008, en el regadío hubo que reducir la superficie de arbolado a la mitad en Yéchar (Mula); en abastecimientos, se recurrió a pozos de sequía y cesiones de derechos. En la de 2017-2018, se han aplicado nuevas tecnologías en sistemas de riego y de cultivo, aparte de algunos aportes de desalinización; en el caso de los abastecimientos, se ha completado la oferta con agua producto de la desalación. La gestión del agua se enfrenta al reto de escenarios de cambio climático en el que serán más frecuentes sucesos extremos como sequías e inundaciones que podrían generar dificultades (fallo de garantía de suministro) para satisfacer las demandas hídrica y alimentaria de una población creciente.
\end{abstract}

\footnotetext{
a Profesora Titular Análisis Geográfico Regional. Departamento de Geografía. Universidad de Murcia. C/ Santo Cristo, 1.30001 Murcia. encargil@um.es.

b Becario FPU (MECD). Departamento de Geografía. Universidad de Murcia. C/ Santo Cristo, 1. 30001 Murcia. miguelborja.bernabe@um.es. [Autor para correspondencia].

c Catedrático Análisis Geográfico Regional. Departamento de Geografía. Universidad de Murcia. C/ Santo Cristo, 1.30001 Murcia. espin@um.es.
}

Fecha de recepción: 20/12/19. Fecha de aceptación: 4/5/20. 
Palabras clave: abastecimientos; regadíos; resiliencia; sequías; sureste de España.

\title{
RESILIENCE IN WATER CONSUMPTION BY SUPPLIES AND IRRIGATION SYSTEMS IN THE FACE OF DROUGHTS IN THE SOUTHEAST OF SPAIN
}

\begin{abstract}
The purpose of this study is to analyze and compare how irrigators and water supply face droughts situations in the 21st century, such as droughts in 2005-2008 and 2017-2018, in the Southeast of Spain. Methodologically, it is a study of Regional Geography with qualitative and quantitative analysis, diachronic and comparative, which includes an extensive field work. Among the sources used, it can be pointed out the historical archives, AEMET data, water consumption data regarding irrigation and urban supply, and interviews with managers and users. The response to droughts of the 21 st century has been different. In the drought of 2005-2008, irrigators had to reduce the area in half in Yéchar (Mula). Regarding water supply, drought wells and transfers of rights were used. In the 2017-2018 drought, new technologies in irrigation and cultivation systems and desalination have been applied. In the case of supplies, the offer has been completed with the contributions of desalination. Water management faces the challenge of climate change scenarios in which extreme events such as droughts and floods will be more frequent and may generate difficulties (supply guarantee failure) to meet the water and food demands of a growing population.
\end{abstract}

KeYwORDs: drought; irrigation; resilience; Southeast of Spain; water supply.

\section{INTRODUCCIÓN}

El concepto de "sequía" varía atendiendo a sus causas y efectos en determinados elementos del medio. Se dice sequía meteorológica (también llamada pluviométrica) la definida por una precipitación escasa y altas tasas de evapotranspiración; la edafológica por el bajo almacenamiento de agua en el suelo; la hidrológica por escorrentías reducidas y bajos niveles de agua subterránea y, la socioeconómica por una disminución del recurso para la producción (CEDEX, 2013:4).

Pereira \& Paulo (2004) definen la sequía como "un déficit temporal de la disponibilidad de agua, de causa natural, originado por lluvias persistentemente inferiores a la media, cuya frecuencia, duración e intensidad son variables y difícilmente predecibles, cuya consecuencia es la disminución del recurso hídrico e impactos en ecosistemas".

En lugares como Israel, la sequía también es un rasgo característico del clima, aunque puede cambiar su zonificación según años secos, lluviosos o promedios (Bruins, 2012). Para categorizar las sequías, hay que tener en cuenta la modificación en la percepción que se ha producido en España a partir de finales del siglo XX. Esta debe realizarse teniendo en cuenta causas físicas y humanas, aunque en la actualidad los aspectos humanos priman sobre los estrictamente físicos (pluviométricos) en la balanza del riesgo de sequía. La intensidad de una sequía y el propio inicio y cese de una secuencia seca vienen 
marcados por los factores humanos (falta de abastecimiento) y menos por el descenso de precipitaciones (Olcina, 2001:202).

Se delimita el Sureste de la Península Ibérica (Figura 1) como el espacio comprendido entre el litoral al sur del Cabo de la Nao (de la Sierra de Bernia, Alicante) y el Cabo de Gata (Almería); y hacia el interior del territorio el límite lo marcan la isoterma de más de $16^{\circ} \mathrm{C}$ y la isoyeta de menos de 400 mm de precipitación anual (Gil, 2014:60). Es la región climática del "Sureste Ibérico", con un número de días despejados que en la mayoría de los observatorios supera más de las cuatro quintas partes de los días del año, elevada luminosidad e insolación, bajo riesgo de heladas y gran irregularidad anual e interanual de las escasas precipitaciones. Los meses secos aumentan de NE a SW, de cinco a nueve meses, con una acusada sequía en verano (Gil \& Gómez, 2015:139). El Sureste ibérico es la región climática española que mayor reducción de lluvia ha padecido en años secos (hasta un 70 \% y más respecto de la precipitación media anual) (Olcina, 2001:211).

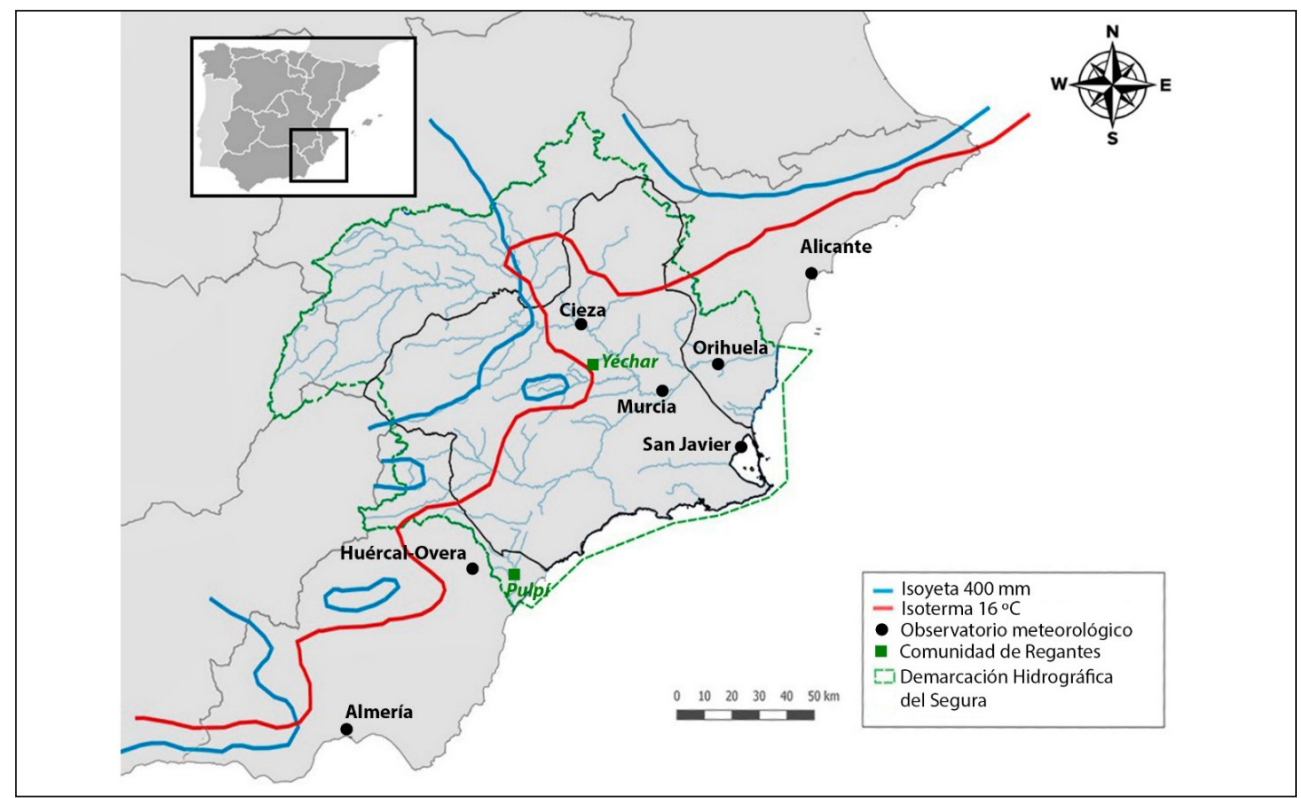

Figura 1. Delimitación del Sureste Ibérico y localización de observatorios y comunidades de regantes analizados. Fuente: elaboración propia.

En este contexto regional, Echegaray (1851) escribía que:

"desgraciadamente las lluvias son allí irregulares, sin periodo, vienen de tarde en tarde, por cuya sequía tan continuada, se hallan aquellos inmensos campos, que se llaman de secano, casi siempre sin cultivo, esperando allí los labradores el agua del cielo como si estuvieran en Palestina" (Echegaray, 1851:8). 
Algunas sequías históricas trajeron el hambre y enfermedades a los habitantes del Reino de Murcia. Rafael Couchoud (1965) cita en el siglo XVI las de los años: 1539 "a causa de la sequía vino un hambre muy grande, que fue seguida de la peste, la cual diezmó la población de España"; 1548 "año de carestía conocido como -año del hambre- y en el que el obispo don Esteban de Almeida socorrió largamente a los necesitados"; 1557 "sequía general en toda España, que vino a superponerse a los quebrantos que las empresas bélicas habían acarreado a la agricultura y al comercio" y 1599 "sequía especialmente acentuada en el alfoz de Cartagena, donde llegó a pagarse el trigo a 34 reales la fanega, de una remesa de mil que se importó de Francia".

La aridificación compromete la disponibilidad hídrica: estudios como el de Gil-Guirado \& Pérez-Morales (2019), muestran que el clima en la ciudad de Murcia ha pasado de un típico mediterráneo con verano caluroso y seco, a un típico mediterráneo semiárido.

La resiliencia es un concepto de larga tradición y creciente interés, Holling (1973) ya hacía referencia a ella como la habilidad de un sistema para mantener su identidad, siendo capaz de adaptar su estructura y función esencial ante los eventos que lo alteran. Folke (2006) añade que el sistema absorbe impactos y se reorganiza. Por lo tanto, es necesario una adaptación que consista en añadir nuevos métodos para sobreponerse a las adversidades medioambientales (O’Briend \& Holland, 1992). El concepto de resiliencia ha sido trabajado por autores como Gil-Guirado (2017) para el ejemplo de Murcia y los sucesos de inundaciones y sequías; o en otros ámbitos como la agroecología (Nicholls \& Altieri, 2012) o la gestión forestal (Lloret, 2012). Para el caso de la relación entre sequías y los abastecimientos de agua en ambientes mediterráneos destaca la obra de Iglesias et al. (2009); Verhagen et al. (2004) inciden en su relación con el cambio climático. Los conceptos de "resiliencia" y "territorios resilientes" podrían aplicarse a una región con escasez estructural de agua como el Sureste español, que ha sido capaz de dinamizar su desarrollo socioeconómico con una larga lucha para superar esa falta de agua, en varios órdenes de actuación.

La adaptación de la agricultura a los periodos de sequía se ha trabajado en diferentes partes del mundo. Altieri \& Nicholls (2013) sugieren que la diversificación de cultivos es un aspecto clave frente al desafío del cambio climático. Kirby et al. (2014) recogen cómo en la cuenca del Murray-Darling (Australia), los regantes hicieron frente a la "sequía del milenio" mediante diversas adaptaciones como el barbecho, sustitución de cultivos, intercambios de agua y mejoras en la tecnología, lo que mejoró su productividad. En la sequía de 2012 en Estados Unidos, algunas estrategias propuestas fueron el cultivo sin labranza, o la diversificación y rotación de las especies de cultivos (Lal et al., 2012). Esta sequía se prolongó durante varios años y propició que se redujera la superficie cultivada, aunque los ingresos seguían siendo altos. Cooley et al. (2015:17) recogen que "los agricultores de California han empleado una variedad de estrategias para responder a la sequía, que incluyen el riego deficitario de sus campos, tierra en barbecho, cambio de cultivos, compra de seguros y bombear más agua subterránea. Las transferencias de agua también han mitigado el impacto de la sequía. En algunos casos, los agricultores con cultivos de menor valor vendieron su agua a los agricultores con cultivos de mayor valor, por lo tanto, reduciendo las pérdidas totales en ingresos agrícolas. Algunos agricultores también vendieron su agua para uso de municipios, industria o medio ambiente". 
La agricultura de regadío en España es especialmente vulnerable al riesgo de sequía hidrológica, que a veces conlleva dotaciones de agua insuficientes para el desarrollo de los cultivos. Por esta razón, resulta necesario un seguro para hacer frente a las pérdidas por "fallo de garantía de suministro" (Gómez-Limón \& Guerrero-Baena, 2019:79). Se reconoce, hoy día, que los sistemas de uso, manejo y gobierno del agua son constructos socio-ambientales, resultado de la hibridación de naturaleza y cultura (Sanchis \& Boelens, 2018:14). Los agentes implicados en procesos de irrigación pueden adaptarse a nuevas realidades en distintos sentidos, como exponen Sanchis-Ibor et al. (2017:45) para el caso de Senyera, Valencia. Por una parte, incluyendo nueva tecnología de riego que envuelve una reforma del sistema de riego; o contrariamente, pueden ser las nuevas técnicas e infraestructuras las que introduzcan cambios en las comunidades de regantes.

El previsible impacto de los procesos de cambio climático sobre los recursos hídricos ha generado un extenso debate sobre las medidas de adaptación necesarias para garantizar la viabilidad de la agricultura de regadío y los abastecimientos (incluyendo los usos turísticos), para integrar la visión de los agricultores y de los gestores del agua en una estrategia participativa de adaptación al cambio global (Ortega-Reig et al., 2018:29 y 30). En este sentido, destacan los intercambios de agua producidos entre regantes y usuarios urbanos, una práctica que puede aliviar crisis temporales pero que puede comprometer la gobernanza a largo plazo (Sanchis-Ibor et al., 2019). Estas medidas paliativas son insuficientes para conformar territorios resilientes, que necesitan de una estrategia más amplia para lograr su seguridad hídrica. El presente trabajo ayuda a conocer cómo han respondido, tanto entidades de abastecimiento urbano como comunidades de regantes, ante diferentes sequías producidas en los primeros años del siglo XXI.

Resulta de gran interés conocer qué repercusiones han tenido las dos últimas sequías en relación con el abastecimiento de agua a la población para consumo humano, y para la agricultura. Esto es especialmente importante en una región donde las sequías son recurrentes debido a las características de su clima y donde los sectores agrícola y turístico constituyen sus principales bazas económicas. Entre los objetivos específicos destaca analizar y evaluar la intensidad de las sequías (meteorológica e hidrológica) en el siglo XXI en el Sureste de España; explicar las respuestas de los usuarios y gestores de abastecimiento y, las respuestas de los regantes y gestores de agua para riego a las sequías. La hipótesis es que el territorio del Sureste español es más resiliente frente a las sequías gracias a la implementación de nuevas técnicas que permiten un mejor rendimiento en el consumo, y a una oferta diversificada de los recursos hídricos.

\section{Metodología}

La investigación es un estudio regional, diacrónico y comparado, sobre un espacio de los más secos de Europa (Sureste de España), donde son frecuentes las sequías meteorológicas e hidrológicas. El análisis cuantitativo y cualitativo, y el conocimiento directo con los agentes de la gestión permiten el diagnóstico de las respuestas de los usuarios del agua ante las sequías, y también plantear una prognosis de propuestas, según escenarios. 
Existen trabajos anteriores (CEDEX, 2013:62) en los que se han planteado las respuestas a sequías como las de 1994-1995, y 2005-2008. En el primer caso sin recurrir a la desalinización; en el segundo, recurriendo a ella. En la última sequía 2017-2018, que aquí se analizará, se estudiará la trascendencia de la desalinización que pasa de recurso complementario a estratégico, a ser contemplada como la "seguridad hídrica" ante las sequías (Rico et al., 2013; Morote, 2018).

Se han tomado los datos de la Agencia Estatal de Meteorología (AEMET) para la caracterización de los periodos secos en el área de estudio. En cuanto a los escenarios regionalizados sobre efectos del cambio climático (en los que se prevén olas de calor más intensas, noches más cálidas y reducción de lluvias), se cuenta con publicaciones como las de AEMET (2017) de Protecciones climáticas para el siglo XXI y del CEDEX (2017) sobre Evaluación del impacto del cambio climático en los recursos hídricos y sequías en España.

Entre las fuentes utilizadas sobresale la consulta de archivos históricos, para tener información de avenidas y sequías históricas en el Sureste como los trabajos de Echegaray (1851) y Couchoud (1965). También se han reunido datos de la Confederación Hidrográfica del Segura (CHS) para contextualizar las existencias del recurso hídrico en el área de estudio. La recogida de datos directos se ha llevado a cabo mediante entrevistas a los gestores de la Mancomunidad de Canales del Taibilla (MCT) en Cartagena, que es el ente encargado del abastecimiento de agua potable en alta a la mayoría de municipios de Murcia y sur de Alicante (así como a los de Férez y Socovos de Albacete). También a los responsables de las comunidades de regantes "La Purísima" de Yéchar (Mula, Murcia) y la de Pulpí (Almería). Estas se han tomado como representativas por el origen del agua consumida en el regadío de 1998-1999 a 2018. Sus fuentes principales de suministro son las aguas trasvasadas (Tajo - Segura o Negratín - Almanzora), y ambas tras la explotación de aguas subterráneas para el inicio de su regadío.

\section{Resultados}

El análisis de las sequías (meteorológicas e hidrológicas) en el espacio del Sureste Ibérico manifiesta cómo afectará a los sistemas productivos agrícolas y, a los usos urbanos y turísticos, así como las medidas de mitigación y adaptabilidad para convertirse en un territorio resiliente a la falta de agua.

\section{Sequías meteorológicas en el Sureste en el siglo XXI}

La escasez pluviométrica deviene de la posición periférica y meridional en la zona de circulación general del oeste de la que derivan: la vecindad de la subsidencia subtropical y el alejamiento de las trayectorias habituales de la corriente en chorro templada. Además, hay un doble sotavento: longitudinal, por su ubicación oriental, y orográfico, al resguardo de las sierras béticas (Gil \& Rico, 2018:17).

Históricamente, ante sequías prolongadas, se ha pedido la lluvia a través de las denominadas rogativas "pro lluvia", en algún caso se ha tenido que recurrir a otro santo e incluso cambiar de santo patrono, como sucedió a finales del siglo XVII en Murcia. Couchoud (1965) cita el año 1692, en el que "se hicieron rogativas a la Virgen de la Arrixaca los días 13 de marzo y 13 de noviembre". En 1694 "el día 17 de enero de este año se trajo por primera vez a la Virgen de la Fuensanta, en procesión de rogativas, 
acompañada por los dos cabildos, desde su pequeño eremeritorio en la tebaida de Ondoyuelo hasta la catedral, y dio tan buenos resultados con lluvias y nevadas abundantes que, en contra de la voluntad del Señor Obispo, fue proclamada patrona de Murcia, y comenzó a desplazar desde ese día a la antiquísima Virgen de la Arrixaca".

Las situaciones atmosféricas proclives a las precipitaciones son escasas, dependen de desarrollos ciclogenéticos mediterráneos (baja de Argel, baja Balear), bajas vinculadas a "gotas frías" sobre el Golfo de Cádiz y situaciones de borde de anticiclón vinculadas a circulaciones de carácter retrogrado (Olcina, 2001:206).

La elección de los observatorios tratados en este trabajo viene dada por la existencia de la misma serie de años (1988-2018) y ubicarse de noreste a sureste en el espacio de estudio (Tabla 1). La representación gráfica nos muestra la gran irregularidad interanual de las precipitaciones (Figuras 2, 3 y 4).

Tabla 1. Extremos pluviométricos de tres de los observatorios analizados (1988-2018).

Fuente: AEMET (2019), elaboración propia.

\begin{tabular}{|l|c|c|c|c|}
\hline \multicolumn{1}{|c|}{ Observatorios } & $\begin{array}{c}\text { Altitud } \\
(\mathrm{msnm})\end{array}$ & $\mathrm{Pm}(\mathrm{mm})$ & $\begin{array}{c}\text { Año más lluvioso } \\
/ \mathbf{P}(\mathbf{m m})\end{array}$ & $\begin{array}{c}\text { Año más seco } \\
/ \mathbf{P}(\mathbf{m m})\end{array}$ \\
\hline Orihuela Desamparados & 26 & 277,65 & $1989 / 547,7$ & $1999 / 137,7$ \\
\hline Cieza Almadenes & 200 & 328,83 & $1989 / 677,2$ & $1994 / 168,7$ \\
\hline Huércal-Overa & 293 & 280,56 & $1989 / 697,4$ & $1993 / 72,3$ \\
\hline
\end{tabular}

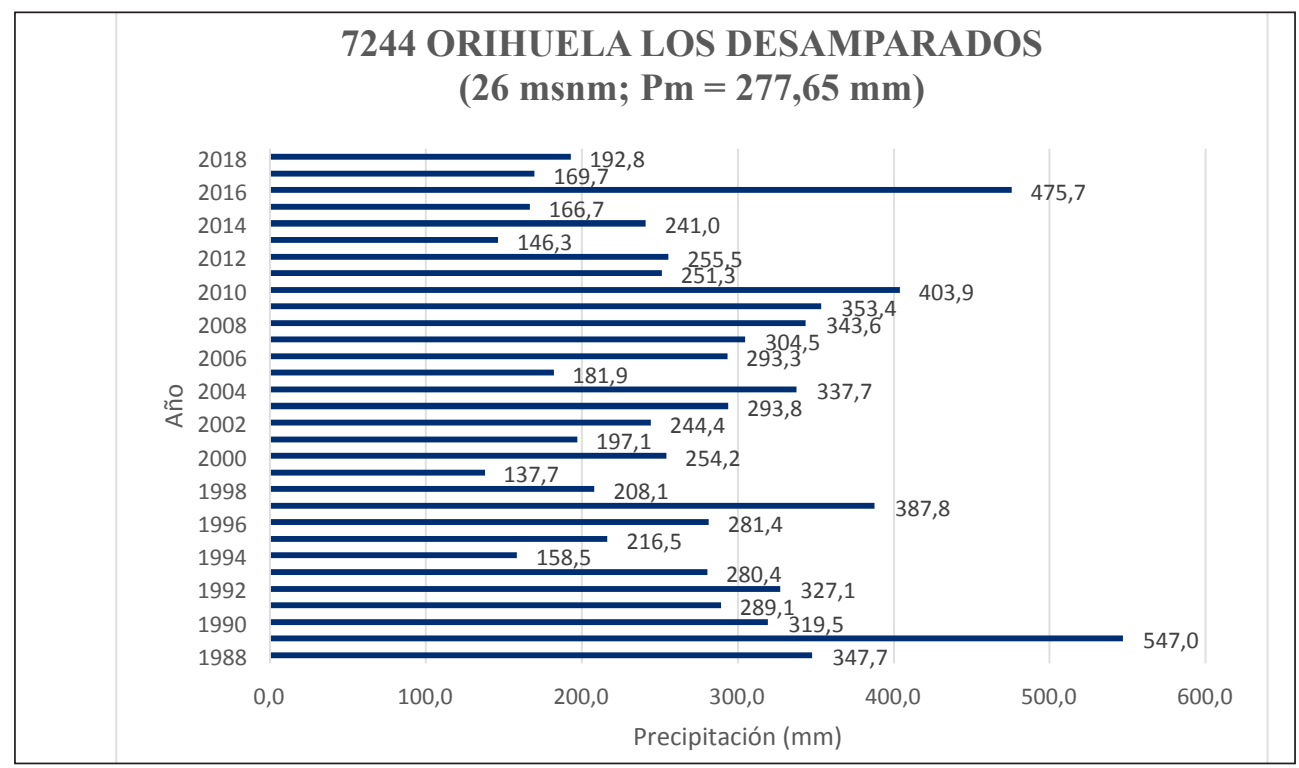

Figura 2. Gráfico de precipitaciones de la estación 7244 Orihuela "Los Desamparados". Fuente: elaboración propia a partir de datos de AEMET (2019). 


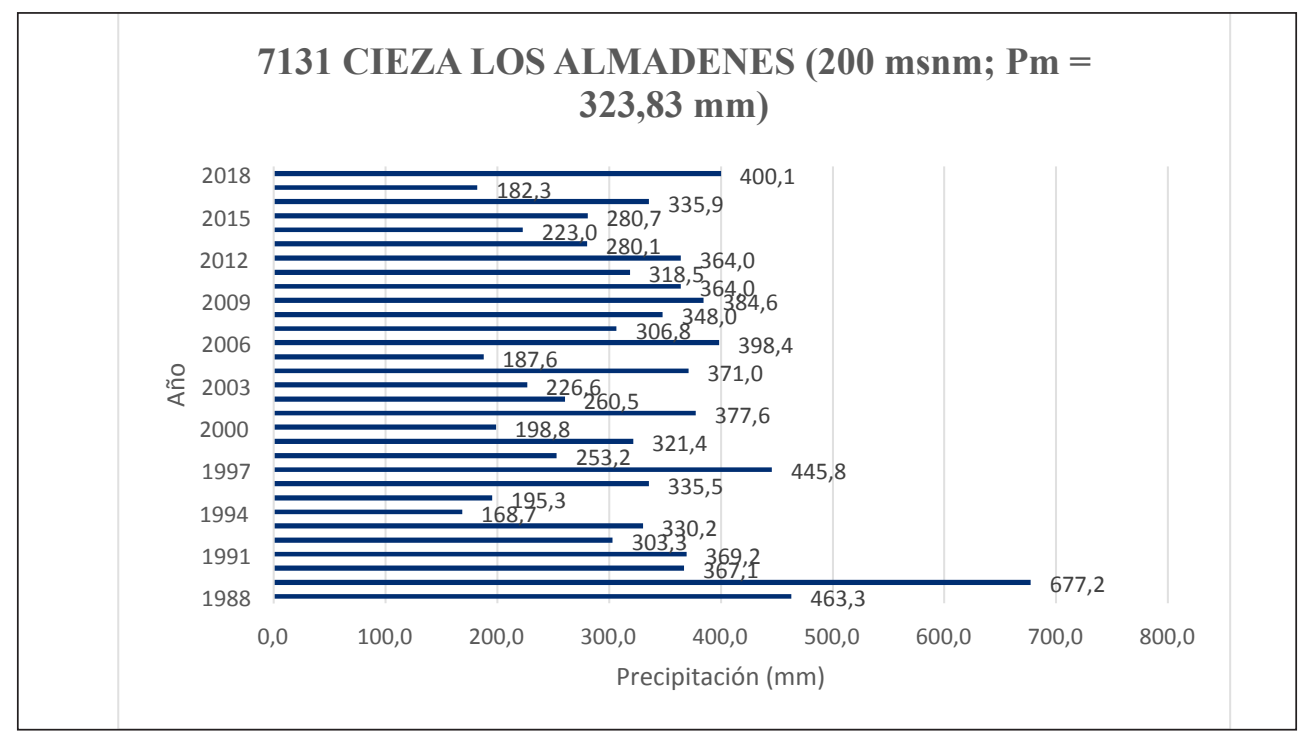

Figura 3. Gráfico de precipitaciones de la estación 7131 Cieza Los Almadenes. Fuente: elaboración propia a partir de datos de AEMET (2019).

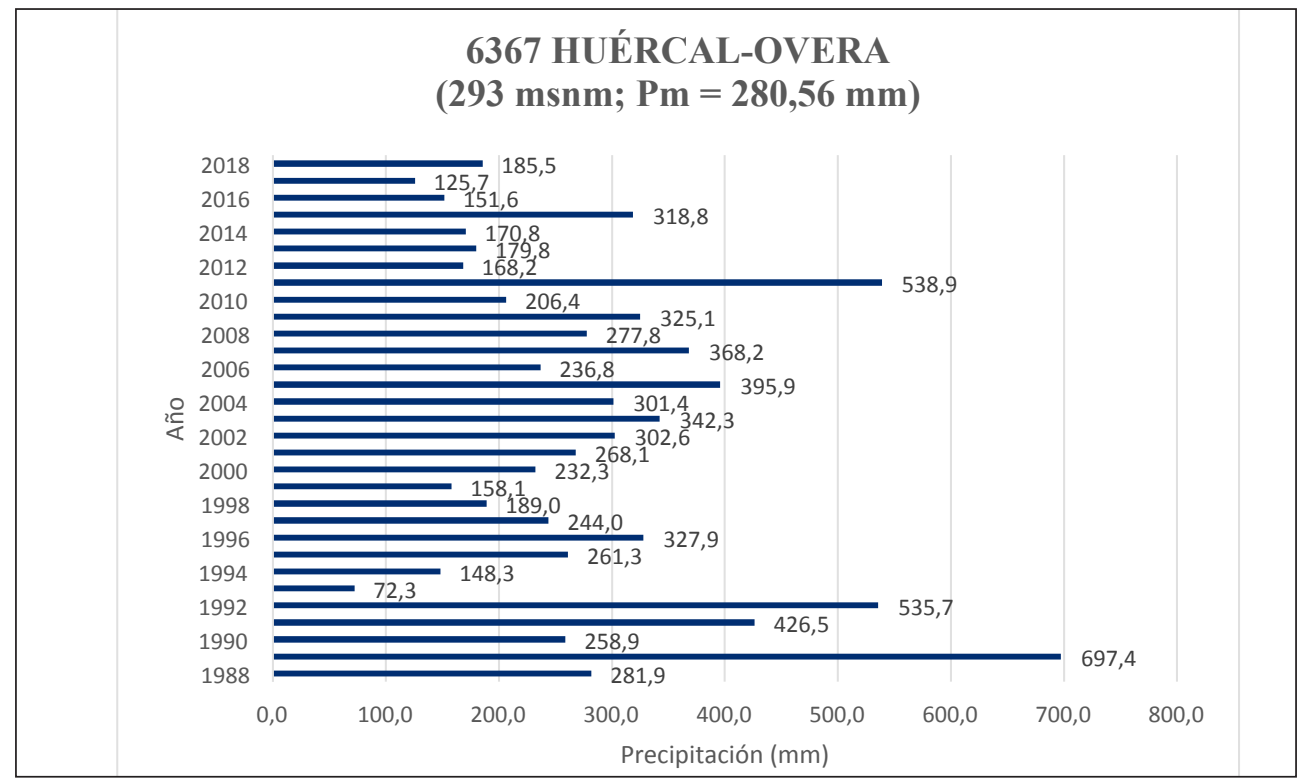

Figura 4. Gráfico de precipitaciones de la estación 6367 Huércal Overa. Fuente: elaboración propia a partir de datos de AEMET (2019). 
Con respecto a los umbrales de sequía son variables atendiendo al lugar geográfico referido y, a la situación de desarrollo regional por la disponibilidad de innovación. Se ha tomado como "año muy seco" aquel cuya precipitación anual se sitúa por debajo del valor de la precipitación media anual restándole la desviación típica o estándar en el periodo analizado. Para determinar los periodos más secos del Sureste se ha ampliado a siete observatorios representativos (Tabla 2).

Los años más secos de la serie analizada, de 1988 a 2018, en el conjunto de esas siete estaciones serían los de 1994, 1995, 1999, 2005, 2014 y 2017; y no tan secos los de 1991, 1993, 1998, 2000, 2001, 2013 y 2015. Como periodos más secos sobresalen 1994-1995, con cinco observatorios; el de 19982001, siendo 1999 el año más seco de este periodo. También 2005, 2013-2015, y 2017, siendo 2014 el año más seco de este periodo.

Tabla 2. Precipitaciones por observatorio según los años más secos en el periodo 1988-2018. Fuente: elaboración propia a partir de datos de AEMET (2019).

\begin{tabular}{|l|c|c|c|c|c|c|c|c|}
\hline \multicolumn{1}{|c|}{ AÑO } & $\begin{array}{c}\text { Huércal- } \\
\text { Overa } \\
<148,69\end{array}$ & $\begin{array}{c}\text { Cieza } \\
<222,96\end{array}$ & $\begin{array}{c}\text { Murcia } \\
<193,17\end{array}$ & $\begin{array}{c}\text { Alicante } \\
<177,05\end{array}$ & $\begin{array}{c}\text { Orihuela } \\
<183,53\end{array}$ & $\begin{array}{c}\text { Almería } \\
<121,04\end{array}$ & $\begin{array}{c}\text { San Javier } \\
<197,95\end{array}$ & TOTAL \\
\hline 1991 & 426,5 & 369,2 & 364,2 & 234,1 & 289,1 & 120,1 & 432,0 & 1 \\
\hline 1993 & 72,3 & 329,6 & 273,7 & 294,1 & 280,4 & 234,6 & 389,3 & 1 \\
\hline 1994 & 148,3 & 168,1 & 148,3 & 170,2 & 158,5 & 271,4 & 260,9 & 5 \\
\hline 1995 & 261,3 & 195,3 & 138,0 & 125,1 & 216,5 & 112,6 & 100,8 & 5 \\
\hline 1998 & 189,0 & 253,2 & 221,0 & 167,3 & 208,1 & 64,9 & 255,4 & 2 \\
\hline 1999 & 158,1 & 321,1 & 132,9 & 173,1 & 137,7 & 218,1 & 159,6 & 4 \\
\hline 2000 & 232,3 & 198,8 & 243,7 & 207,2 & 254,2 & 250,1 & 276,1 & 1 \\
\hline 2001 & 268,1 & 377,6 & 330,9 & 474,7 & 197,1 & 113,9 & 430,5 & 1 \\
\hline 2005 & 395,9 & 187,3 & 199,3 & 207,5 & 181,9 & 120,7 & 236,4 & 3 \\
\hline 2013 & 179,8 & 280,1 & 231,3 & 194,5 & 146,3 & 140,5 & 258,4 & 1 \\
\hline 2014 & 170,8 & 223,0 & 186,5 & 130,0 & 241,0 & 126,6 & 179,4 & 4 \\
\hline 2015 & 318,8 & 280,7 & 236,5 & 206,3 & 166,7 & 254,5 & 274,4 & 1 \\
\hline 2017 & 125,7 & 182,3 & 177,9 & 296,5 & 169,7 & 185,9 & 169,6 & 5 \\
\hline $\begin{array}{l}\text { Total Años } \\
\text { Muy Secos }\end{array}$ & 3 & 6 & 5 & 5 & 6 & 5 & 4 & \\
\hline
\end{tabular}

\section{Sequías hidrológicas en el Sureste en el siglo XXI}

Para el análisis de las sequías hidrológicas (falta de disponibilidad de agua) se han consultado los datos de agua embalsada en la cuenca del Segura, proporcionados por la Confederación Hidrográfica del Segura (CHS). Se considera el umbral de la sequía hidrológica, en este trabajo, cuando no se supera 
en la existencia de agua embalsada en la cuenca el $25 \%$ de la capacidad total de sus embalses. Para la Cuenca del Segura, se ha analizado el periodo de 34 años que va de 01/10/1986 a 01/10/2019 (Tabla 3). Como años de acusada falta de agua (solo el $10 \%$ de la capacidad), destacan los de 1986-1988; 1991-1995; 2003; y 2005-2006. Como años secos, (aquellos que no superan el 25 \%), estarían los de 1989-1990; 1996-2002; 2004; 2007-2008; y 2016-2018.

Tabla 3. Existencias de agua en los embalses de la Cuenca del Segura (1986-2019). Fuente: Confederación Hidrográfica del Segura (CHS).

\begin{tabular}{|c|c|c|c|c|}
\hline FECHA & $\begin{array}{l}\text { Agua Embalsada } \\
\text { Cuenca }\left(h^{3}\right)\end{array}$ & $\begin{array}{c}\text { Agua Embalsada Cuenca + } \\
\text { Trasvase }\left(\mathrm{hm}^{3}\right)\end{array}$ & $\begin{array}{l}\text { Capacidad Embalse } \\
\qquad\left(\mathrm{hm}^{3}\right)\end{array}$ & $\begin{array}{l}\text { Existencias De } \\
\text { Agua (\%) }\end{array}$ \\
\hline 01/10/1986 & 72,25 & 72,65 & 1.057 & $7 \%$ \\
\hline 01/10/1987 & 4,8 & 58,53 & 1.057 & $6 \%$ \\
\hline 01/10/1988 & 35,72 & 98,58 & 1.057 & $9 \%$ \\
\hline 01/10/1989 & 131,23 & 180,8 & 1.057 & $17 \%$ \\
\hline 01/10/1990 & 196,49 & 216,35 & 1.057 & $20 \%$ \\
\hline 01/10/1991 & 98,75 & 99,33 & 1.057 & $9 \%$ \\
\hline 01/10/1992 & 84,91 & 82,07 & 1.057 & $8 \%$ \\
\hline 01/10/1993 & 69,63 & 69,63 & 1.057 & $7 \%$ \\
\hline 01/10/1994 & 65,49 & 65,01 & 1.057 & $6 \%$ \\
\hline 01/10/1995 & 60,18 & 74,16 & 1.057 & $7 \%$ \\
\hline 01/10/1996 & 120,99 & 156,75 & 1.057 & $15 \%$ \\
\hline 01/10/1997 & 158,26 & 256,03 & 1.057 & $24 \%$ \\
\hline 01/10/1998 & 174,66 & 259,66 & 1.057 & $25 \%$ \\
\hline 01/10/1999 & 41,28 & 113,63 & 1.057 & $11 \%$ \\
\hline 01/10/2000 & 16,34 & 142,43 & 1.057 & $13 \%$ \\
\hline 01/10/2001 & 57,67 & 163 & 1.057 & $15 \%$ \\
\hline 01/10/2002 & 8,75 & 125,88 & 1.057 & $12 \%$ \\
\hline $01 / 10 / 2003$ & 31,02 & 81,14 & 1.057 & $8 \%$ \\
\hline 01/10/2004 & 119,04 & 169,381 & 1.057 & $16 \%$ \\
\hline 01/10/2005 & 52,081 & 107,554 & 1.057 & $10 \%$ \\
\hline 01/10/2006 & 45,436 & 99,973 & 1.057 & $9 \%$ \\
\hline $01 / 10 / 2007$ & 47,297 & 126,562 & 1.057 & $12 \%$ \\
\hline 01/10/2008 & 51,49 & 143,464 & 1.057 & $14 \%$ \\
\hline 01/10/2009 & 165,703 & 270,896 & 1.057 & $26 \%$ \\
\hline
\end{tabular}




\begin{tabular}{|c|c|c|c|c|}
\hline FECHA & $\begin{array}{c}\text { Agua Embalsada } \\
\text { Cuenca }\left(\mathrm{hm}^{3}\right)\end{array}$ & $\begin{array}{c}\text { Agua Embalsada Cuenca }+ \\
\text { Trasvase }\left(\mathrm{hm}^{3}\right)\end{array}$ & $\begin{array}{c}\text { Capacidad Embalse } \\
\left(\mathrm{hm}^{3}\right)\end{array}$ & $\begin{array}{c}\text { Existencias De } \\
\text { Agua (\%) }\end{array}$ \\
\hline $01 / 10 / 2010$ & 493,165 & 619,796 & 1.057 & $59 \%$ \\
\hline $01 / 10 / 2011$ & 516,809 & 620,044 & 1.057 & $59 \%$ \\
\hline $01 / 10 / 2012$ & 350,204 & 421,268 & 1.057 & $40 \%$ \\
\hline $01 / 10 / 2013$ & 630,099 & 721,822 & 1.057 & $68 \%$ \\
\hline $01 / 10 / 2014$ & 597,967 & 648,078 & 1.057 & $61 \%$ \\
\hline $01 / 10 / 2015$ & 431,727 & 445,233 & 1.057 & $42 \%$ \\
\hline $01 / 10 / 2016$ & 209,644 & 245,877 & 1.057 & $23 \%$ \\
\hline $01 / 10 / 2017$ & 86,957 & 132,291 & 1.057 & $13 \%$ \\
\hline $01 / 10 / 2018$ & 130,417 & 214,506 & 1.057 & $20 \%$ \\
\hline $01 / 10 / 2019$ & 108,69 & 267,841 & 1.057 & $25 \%$ \\
\hline
\end{tabular}

En realidad, ha habido que esperar a casi los últimos años (2009-2015) de la serie analizada (19882018) para que el agua embalsada en la cuenca (la de la propia cuenca y la del Trasvase Tajo - Segura (TTS) significase más del 25 \% de la capacidad total de embalse. En los años (1988-2018), los periodos de sequía meteorológica acusada y los de sequía hidrológica han sido varios en la región del Sureste (Tabla 4).

Tabla 4. Sequías meteorológicas (SM) e hidrológicas (SH) en estaciones del Sureste (19882018). Fuente: elaboración propia.

\begin{tabular}{|l|l|l|l|l|}
\hline \multirow{2}{*}{ Años } & \multicolumn{2}{c|}{ Sequía meteorológica SM } & \multicolumn{2}{c|}{ Sequía hidrológica SH } \\
\hline & SM MUY SECOS & SM SECOS & SH ACUSADA & SH MODERADA \\
\hline 1988 & & & & \\
\hline 1989 & & & & \\
\hline 1990 & & & & \\
\hline 1991 & & & & \\
\hline 1992 & & & & \\
\hline 1993 & & & & \\
\hline 1994 & & & & \\
\hline 1995 & & & & \\
\hline 1996 & & & & \\
\hline 1997 & & & & \\
\hline 1998 & & & & \\
\hline
\end{tabular}




\begin{tabular}{|c|c|c|c|c|}
\hline \multirow{2}{*}{ Años } & \multicolumn{2}{|c|}{ Sequía meteorológica SM } & \multicolumn{2}{|c|}{ Sequía hidrológica SH } \\
\hline & SM MUY SECOS & SM SECOS & SH ACUSADA & SH MODERADA \\
\hline 1999 & & & & \\
\hline 2000 & & & & \\
\hline 2001 & & & & \\
\hline 2002 & & & & \\
\hline 2003 & & & & \\
\hline 2004 & & & & \\
\hline 2005 & & & & \\
\hline 2006 & & & & \\
\hline 2007 & & & & \\
\hline 2008 & & & & \\
\hline 2009 & & & & \\
\hline 2010 & & & & \\
\hline 2011 & & & & \\
\hline 2012 & & & & \\
\hline 2013 & & & & \\
\hline 2014 & & & & \\
\hline 2015 & & & & \\
\hline 2016 & & & & \\
\hline 2017 & & & & \\
\hline 2018 & & & & \\
\hline
\end{tabular}

En los años 1994, 1995 y 2005 se produjo la coincidencia de sequía meteorológica de años muy secos y sequía hidrológica acusada. En realidad, el periodo libre de cualquier sequía solo se ha producido de 2009 a 2012. En lo que afecta a la disponibilidad de agua para la cuenca del Segura, se amplió esa situación hasta 2015. Desde 2016 se cuenta con una sequía hidrológica moderada, a pesar de años muy secos como 2014 y 2017 (Gil-Meseguer et al., 2019a). Los días 12 y 13 de septiembre de 2019 las precipitaciones asociadas a DANA (depresión aislada en niveles altos) superaron en la Cuenca del Segura el valor de precipitación media arealde $126,7 \mathrm{~mm}$, equivalente a un volumen bruto de $2.438 \mathrm{hm}^{3}$; de los que sólo se pudieron recoger en los embalses $70 \mathrm{hm}^{3}$ (CHS-SAIHSEGURA).

\section{Discusión}

A veces coinciden sequías meteorológica e hidrológica, y como resultado, falta de agua para atender las necesidades de abastecimientos, regadíos y otros usos. Estas crisis comprometen el desarrollo 
regional del Sureste, muy dependiente de una agricultura de regadío y de las actividades derivadas de ella. También del turismo, que masivamente se da en el verano, cuando las temperaturas son más elevadas y más profunda la sequía mediterránea. Las respuestas han sido diversas. Para hacer frente a las sequías en este espacio se han planteado políticas de ofertas de recursos y políticas de control de las demandas, y en los últimos años se ha planteado la gestión integrada de recursos y demandas (Gil-Meseguer et al., 2017).

Gestión integrada de oferta y demanda de agua que suponen, en el mix de oferta, los recursos convencionales (aguas superficiales, subterráneas y trasvasadas) y los no convencionales (reutilización de aguas residuales regeneradas, desalinización de salobres continentales y agua marina, y aprovechamiento de pluviales). Y entre las medidas de gestión de la demanda, en el ámbito agrícola, riegos a la demanda, precios del agua, modernización de regadíos, selección de cultivos, empleo de energías renovables asociadas a captación y distribución del agua, etc. y, en el ámbito del abastecimiento de demandas urbanas, industriales y turísticas, hábitos de ahorro de agua, precios del agua en alta y baja, mejora de la eficacia de las redes de distribución, innovaciones tecnológicas, mayor control de vertidos, energías renovables en generación de agua caliente, etc. En definitiva, reducir la vulnerabilidad ante el riesgo de sequía y aumentar la capacidad de adaptación ante el calentamiento global y cambio climático.

\section{Consumo de agua para riego en situaciones de sequía}

Entre las distintas comunidades de regantes, que se han organizado para el riego de las tierras en el Sureste, hemos estudiado el caso de la C.R. "La Purísima" de Yéchar (Mula, Murcia) y la C.R. de Pulpí (Almería).

La primera Comunidad tiene actualmente un área regable de 777,65 ha y 267 regantes. Se le asignó una dotación del TTS de hasta 4 hm³/año. En su orientación productiva han predominado los frutales de hueso (sobre todo albaricoquero), en menor medida, olivar, cítricos y hortalizas (Gómez et al., 2011:197). Dentro del predominio de los frutales de hueso destacan las variedades tempranas de albaricoque y melocotón, especialmente aquellas con mayor demanda en los mercados exteriores (López et al., 2017:186). Actualmente la ocupación del suelo es del 40 \% de albaricoqueros, 20 \% de melocotoneros, 10 \% de limón, $10 \%$ de olivar, y el resto con hortalizas y en blanco (barbechos).

Según los datos de la disponibilidad de recursos para riego en la C. R. "La Purísima" de Yéchar (Tabla 5), se observan, en el periodo 1999-2018, dos importantes sequías hidrológicas: la de 2005-2008 y la de 2017-2018. En la primera, el año de menos recursos fue 2007 (960.000 m³/año) y en la segunda el de 2018 (1.266.623 mªño), coincidiendo con sequías en la cabecera del Tajo en ambos casos. En el primer caso, ante el descenso tan acusado de la aportación del Trasvase Tajo - Segura, se recurre a pozos de sequía y cesiones temporales de derechos; pero que apenas consiguen alcanzar un tercio de lo que era el volumen habitual del trasvase, por lo que tuvieron que adoptar la medida de disminuir el $50 \%$ de sus demandas recurriendo al arranque de arbolado con pérdida de patrimonio rústico (López-Fernández et al., 2017:184). La situación de falta de disponibilidad de recursos se prolongó en los años 2009 y 2010. 
Tabla 5. Volúmenes de agua $\left(\mathrm{m}^{3}\right)$ consumidos en la C. R. "La Purísima" de Yéchar (Mula).

Fuente: elaboración propia a partir de datos de C. R. "La Purísima", Yéchar.Nota: *Entre los pozos de sequía se incluyen aguas del Sinclinal de Calasparra, de La Pedrera y de la cuenca del Segura. ${ }^{\star \star}$ Más de la mitad de las cesiones temporales de derechos corresponden a la C.R. de Estremera (Madrid).

\begin{tabular}{|c|c|c|c|c|c|c|}
\hline AÑOS & $\begin{array}{c}\text { TRASVASE } \\
\text { TAJO- } \\
\text { SEGURA }\end{array}$ & $\begin{array}{c}\text { POZOS } \\
\text { DE } \\
\text { SEQUÍA* }\end{array}$ & $\begin{array}{c}\text { POZO } \\
\text { ESCARIHUELA }\end{array}$ & $\begin{array}{l}\text { CESIONES DE } \\
\text { DERECHOS** }\end{array}$ & $\begin{array}{c}\text { DESALADORA } \\
\text { TORREVIEJA }\end{array}$ & TOTAL \\
\hline 1999 & 2.700 .000 & - & - & - & - & 2.700 .000 \\
\hline 2000 & 3.400 .000 & - & - & - & - & 3.400 .000 \\
\hline 2001 & 3.200 .000 & - & - & - & - & 3.200 .000 \\
\hline 2002 & 3.100 .000 & - & - & - & - & 3.100 .000 \\
\hline 2003 & 3.100 .000 & - & - & - & - & 3.100 .000 \\
\hline 2004 & 2.750 .000 & - & - & - & - & 2.750 .000 \\
\hline 2005 & 340.000 & 132.000 & 100.000 & 500.000 & - & 1.072 .000 \\
\hline 2006 & 460.000 & 528.000 & 100.000 & 358.300 & - & 1.446 .300 \\
\hline 2007 & 380.000 & 120.000 & 100.000 & 360.000 & - & 960.000 \\
\hline 2008 & 694.954 & 359.022 & 70.000 & 303.669 & - & 1.427 .645 \\
\hline 2009 & 1.004 .894 & 29.619 & 50.000 & 166.289 & - & 1.250 .802 \\
\hline 2010 & 1.200 .000 & - & 23.400 & - & - & 1.223 .400 \\
\hline 2011 & 1.574 .000 & - & 20.000 & - & - & 1.594 .000 \\
\hline 2012 & 2.169 .590 & - & 96.197 & - & - & 2.265 .787 \\
\hline 2013 & 1.981 .000 & - & 10.000 & 263.000 & - & 2.254 .000 \\
\hline 2014 & 2.900 .000 & - & 86.000 & - & - & 2.986 .000 \\
\hline 2015 & 1.647 .000 & 427.185 & 65.000 & - & - & 2.139 .185 \\
\hline 2016 & 927.000 & 290.791 & 200.000 & 930.501 & 313.304 & 2.661 .596 \\
\hline 2017 & 782.500 & 250.000 & 165.900 & - & 338.300 & 1.536 .700 \\
\hline 2018 & 945.000 & 107.523 & 174.100 & - & 40.000 & 1.266 .623 \\
\hline
\end{tabular}

Sin embargo, en la sequía 2017-2018, el descenso de las aportaciones trasvasadas (TTS) fue compensado con pozos de sequía, con la sobreexplotación del pozo de la Escarihuela y con recursos desalados procedentes de Torrevieja (Figura 5). Como el "mix hídrico" total alcanzaba aproximadamente la mitad de lo que era su disponibilidad media, se han aplicado también técnicas de riego deficitario en vez del arranque de arbolado. La participación de las aguas de la desaladora de Torrevieja ha llevado consigo un incremento del precio de agua al regante (aunque el agua más cara es la que no se tiene, estos volúmenes de desalación han significado un incremento en el recibo de los usuarios). En las entrevistas realizadas, los gestores de la C.R. manifestaban que "el precio del agua desalada no es asequible". 
El agua de desalación que han recibido duplica el coste medio del $\mathrm{m}^{3}$ del agua que facilitaban a sus explotaciones (menos de $0,15 € / \mathrm{m}^{3}$ ). De ahí que opinen que las actuales masas de cultivo no las podrían mantener sólo con estos precios tan elevados del agua de desalación (más de $0,30 € / \mathrm{m}^{3}$ ).

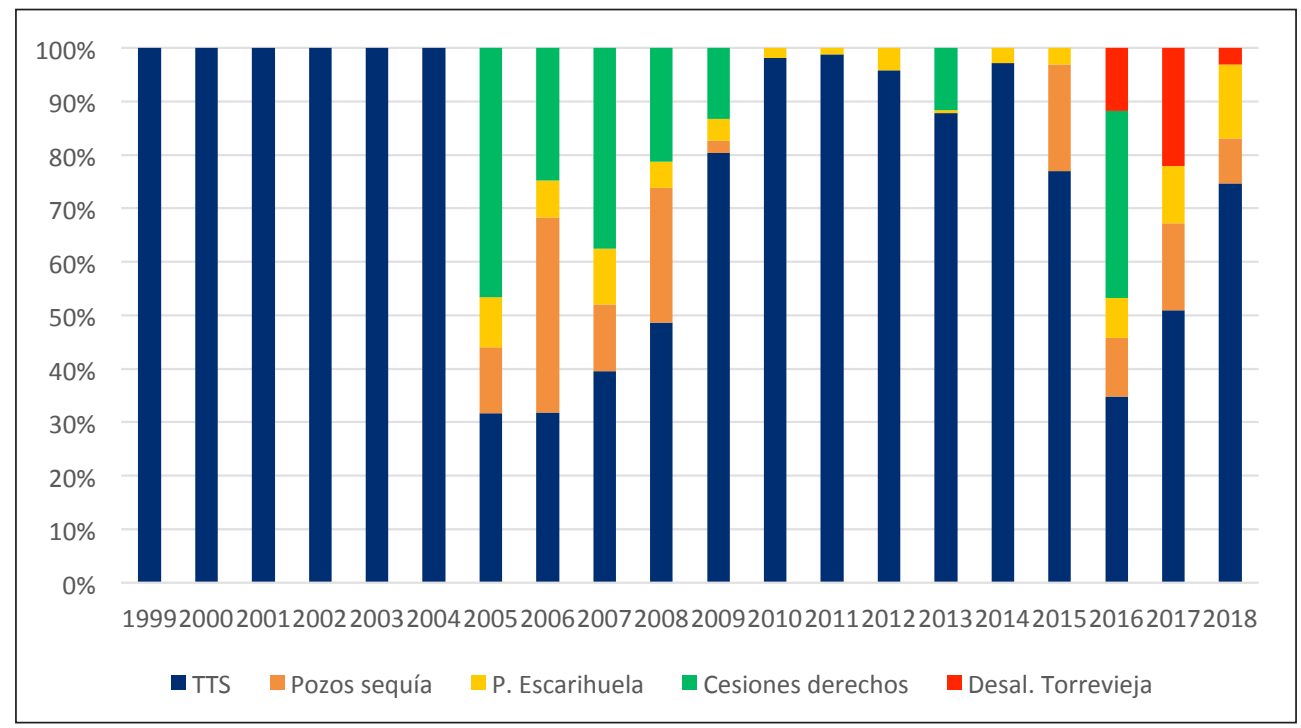

Figura 5. Consumos de agua para riego, según origen, en el periodo 1999-2018 en la C. R. "La Purísima" de Yéchar (Mula), volúmenes (\%). Fuente: elaboración propia a partir de datos de C. R. "La Purísima" de Yéchar (Mula).

La C. R. de Pulpí se crea el 15/04/1983, por Resolución del Ministerio de Obras Públicas (Gil et al., 2014:34). En la actualidad, la componen 1.241 regantes y tiene una superficie regable de 8.577,97 ha. Los principales cultivos son cítricos (sobre todo naranjas y mandarinas), hortalizas (lechugas, brócoli, cebollas, ajos, etc.), frutas como melón y sandía, y algunos tubérculos. Entre las concesiones de agua para riego sobresalen las aguas de los pozos de Esparragal (en el Alto Guadalentín) y del Cortijo San Carlos (Calasparra), a las que se han unido los volúmenes de la Conexión Negratín - Almanzora (C $\mathrm{N}$-A) de hasta más de 14,58 hm³/año, y más recientemente las aguas procedentes de las desaladoras del Bajo Almanzora, más de 4 hm³/año, y de Águilas-Guadalentín, más de $5 \mathrm{hm}^{3} /$ año. La comunidad se encuentra totalmente modernizada, completadas las tres fases de la primera generación de modernización, y con alguna experiencia de segunda generación (ya hay cubierto un embalse para reducir pérdidas por evaporación).

En ambas sequías, al estar totalmente modernizado el sistema de riego, se pudo controlar el consumo de cada regante y se restringió la dotación de los comuneros. En la primera sequía (2005-2008) se intensifican las cesiones de derechos y las aguas del trasvase Negratín - Almanzora (Tabla 6). 
Tabla 6. Volúmenes de agua (en $\mathrm{m}^{3}$ ) consumidos en la C. R. de Pulpí (Almería). Fuente: elaboración propia a partir de datos de C. R. de Pulpí. *Incluye hasta 31-12-2015.

\begin{tabular}{|c|c|c|c|c|c|c|}
\hline Año & $\begin{array}{c}\text { Pozos Esparragal } \\
\text { y Calasparra }\end{array}$ & $\begin{array}{c}\text { T. Tajo } \\
\text { - Segura } \\
\text { (TTS) }\end{array}$ & $\begin{array}{l}\text { Otras aguas } \\
\text { (cesiones de } \\
\text { derechos) }\end{array}$ & $\begin{array}{l}\text { Desaliniza- } \\
\text { ción }\end{array}$ & $\begin{array}{c}\text { T. Negratín - } \\
\text { Almanzora } \\
\text { (C N-A) }\end{array}$ & Total \\
\hline $98-99$ & 11.108 .634 & 6.053 .502 & 2.652 .300 & - & - & 19.814 .436 \\
\hline $99-00$ & 9.727 .945 & 3.161 .245 & 1.895 .600 & 5.417 .866 & - & 20.202 .656 \\
\hline $00-01$ & 6.822 .734 & 1.425 .000 & 5.637 .036 & 5.381 .434 & - & 19.266 .204 \\
\hline $2001-2$ & 5.861 .488 & 3.869 .206 & 3.084 .640 & 5.101 .333 & - & 17.916 .667 \\
\hline 2002-03 & 4.043 .445 & 2.115 .843 & 2.852 .002 & 5.566 .422 & 648.190 & 15.225 .902 \\
\hline $2003-04$ & 4.142 .051 & 1.768 .798 & 1.643 .590 & 3.560 .173 & 6.889 .086 & 18.003 .698 \\
\hline 2004-05 & 3.192 .568 & 2.209 .150 & 574.724 & 2.079 .315 & 14.392 .240 & 22.447 .997 \\
\hline 2005-06 & 3.163 .676 & - & 2.172 .015 & 3.432 .667 & 8.779 .360 & 17.547 .718 \\
\hline $2006-07$ & 2.267 .654 & - & 2.948 .639 & 3.015 .963 & 11.389 .400 & 19.621 .656 \\
\hline $2007-08$ & 3.186 .653 & - & 4.463 .532 & 1.227 .986 & 11.577 .790 & 20.455 .961 \\
\hline 2008-09 & 2.572 .893 & 231.836 & 2.533 .563 & 2.553 .277 & 13.674 .180 & 21.565 .749 \\
\hline $2009-10$ & 2.933 .325 & - & 3.234 .914 & 1.932 .904 & 15.267 .590 & 23.368 .733 \\
\hline $2010-11$ & 603.476 & 307.900 & 6.313 .743 & 1.722 .106 & 18.136 .140 & 27.083 .365 \\
\hline $2011-12$ & 639.451 & 439.826 & 4.474 .011 & 1.925 .350 & 20.137 .770 & 27.616 .408 \\
\hline $2012-13$ & 2.011 .590 & 301.794 & 1.250 .395 & 3.340 .381 & 22.925 .710 & 29.829 .870 \\
\hline $2013-14$ & 220.170 & 379.837 & 4.133 .119 & 7.009 .670 & 23.152 .256 & 34.895 .052 \\
\hline $2014-2015 *$ & 983.183 & 294.118 & - & 10.467 .595 & 29.649 .260 & 41.394 .156 \\
\hline 2016 & 890.861 & 163.750 & - & 8.756 .517 & 20.933 .070 & 30.744 .198 \\
\hline 2017 & 580.232 & 269.056 & - & 11.610 .391 & 14.161 .971 & 26.621 .650 \\
\hline 2018 & 741.212 & 127.885 & - & 10.659 .727 & 13.754 .317 & 25.283 .141 \\
\hline
\end{tabular}

En la sequía 2017-2018 ha disminuido la participación de los pozos, de las cesiones de derechos e incluso del Negratín - Almanzora, por lo que se ha tenido que recurrir a volúmenes tratados en desaladoras y desalobradoras (Figura 6). El incremento de la desalación aumenta el precio final del mix del agua, pero garantiza el suministro. Les aporta cierta "seguridad hídrica", les permite planificar las campañas de plantación de hortícolas y, disponen de agua para el riego de cítricos. 


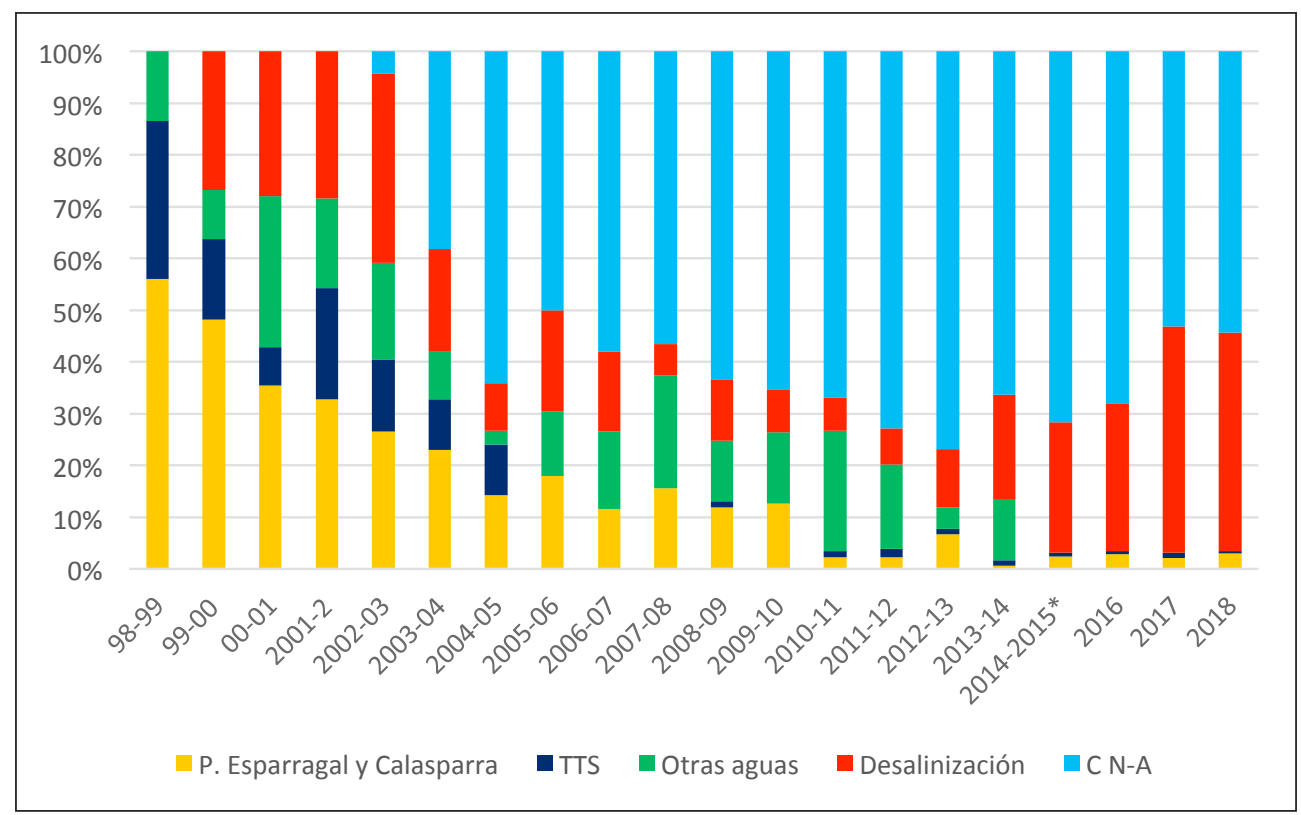

Figura 6. Consumos de agua para riego en \%, según origen, en el periodo 1999-2018 en la C.R. de Pulpí (Almería). Fuente: elaboración propia a partir de datos de C.R. Pulpí.

En esta última sequía se hizo necesario para garantizar el abastecimiento el incorporar bombeos, hasta ese momento innecesarios por el diseño del plan de modernización, para paliar la falta de presión debido al descenso del volumen almacenado en los embalses. Además, los comuneros han incorporado nuevas técnicas basadas en sistemas de riego deficitario para aprovechar mejor el agua. En las entrevistas realizadas a los gestores de la C.R, estos expresaban que "los regantes consumen menos agua para sacar adelante la plantación".

Si bien estas comunidades de regantes analizadas no tienen participación de las Estaciones Depuradoras de Aguas Residuales (EDAR), en la Región de Murcia la práctica totalidad de estos caudales son reutilizados, como muestran estudios como el de Gil-Meseguer, Bernabé-Crespo y Gómez-Espín (2019b) y son para algunas Comunidades de Regantes garantía de mantener arbolado en épocas de sequía.

Consumo de agua para abastecimiento en situaciones de sequía

La Mancomunidad de los Canales del Taibilla (MCT), creada en 1927, es el órgano encargado de la distribución del agua en alta para abastecimientos en buena parte del cuadrante sureste de la península Ibérica.

En el análisis del agua para abastecimiento (Tabla 7), se observa que en la primera sequía del siglo XXI (2005-2008), ante la bajada del agua trasvasada desde el Tajo (34,54 \% del total) y la disminución 
de los caudales aportados por el Taibilla (16,24\%), se recurrió a incrementar las cesiones temporales de derechos (16,52 \%). Comienza una progresiva participación de la desalación, que en 2005 apenas llegaba al 9,50 \% porque todavía no se encontraba desarrollada, aunque en 2008 llegó al 32,70 \%. En la segunda sequía (2017-2018), ha sido acusado el descenso de las aguas transferidas del Tajo-Segura $(25,96 \%)$ y del Taibilla (24,37 \%). La situación se ha compensado con un incremento de la desalación hasta significar el 47,62 \%, haciendo uso de las grandes capacidades instaladas durante los años anteriores. El 32,66 \% del agua de la MCT procede de sus cuatro plantas desaladoras (Figura 7) (y el $14,96 \%$ procede de otras desaladoras de Acuamed). Los recursos extraordinarios (sobre todo, cesiones temporales de derechos), apenas significaron el 2,05\%.

Tabla 7. Volúmenes de agua distribuidos por MCT según origen $\left(\mathrm{m}^{3}\right)$.

Fuente: elaboración propia a partir de MCT (2019). *Incluye cesiones temporales de derechos.

\begin{tabular}{|l|c|c|c|c|c|}
\hline AÑO & Taibilla & ATS & Suma Otros* & Desalación & Total \\
\hline 1999 & 51.644 .134 & 138.782 .020 & 1.118 .728 & & 191.544 .882 \\
\hline 2000 & 44.137 .834 & 144.715 .808 & 9.568 .905 & - & 198.422 .547 \\
\hline 2001 & 44.517 .551 & 139.449 .073 & 20.339 .501 & - & 204.306 .125 \\
\hline 2002 & 41.848 .555 & 119.134 .371 & 46.618 .790 & & 207.601 .716 \\
\hline 2003 & 37.902 .293 & 160.714 .500 & 10.611 .352 & 5.014 .940 & 214.243 .085 \\
\hline 2004 & 43.363 .868 & 123.734 .069 & 36.867 .605 & 16.817 .311 & 220.782 .853 \\
\hline 2005 & 39.432 .818 & 124.416 .667 & 41.785 .205 & 21.650 .116 & 227.284 .806 \\
\hline 2006 & 36.861 .255 & 103.411 .916 & 43.097 .959 & 42.011 .319 & 225.382 .449 \\
\hline 2007 & 38.550 .286 & 113.673 .634 & 13.559 .989 & 60.248 .708 & 226.032 .617 \\
\hline 2008 & 35.950 .551 & 76.441 .454 & 36.569 .654 & 72.358 .062 & 221.319 .721 \\
\hline 2009 & 47.383 .221 & 94.842 .768 & 724.230 & 72.610 .030 & 215.560 .249 \\
\hline 2010 & 57.851 .490 & 86.646 .585 & 1.240 .878 & 56.195 .971 & 201.934 .924 \\
\hline 2011 & 60.140 .391 & 104.113 .615 & 957.066 & 34.869 .571 & 200.080 .643 \\
\hline 2012 & 49.004 .427 & 98.023 .951 & 3.333 .112 & 44.033 .220 & 194.394 .710 \\
\hline 2013 & 72.113 .547 & 99.530 .954 & 6.109 .106 & 6.273 .140 & 184.026 .747 \\
\hline 2014 & 57.290 .548 & 113.833 .804 & 824.319 & 11.225 .740 & 183.174 .411 \\
\hline 2015 & 55.366 .240 & 87.899 .648 & 3.487 .680 & 38.562 .150 & 185.315 .718 \\
\hline 2016 & 49.824 .176 & 72.497 .615 & 5.048 .167 & 59.506 .928 & 186.876 .886 \\
\hline 2017 & 52.696 .225 & 36.298 .995 & 19.287 .414 & 85.370 .329 & 193.652 .963 \\
\hline 2018 & 47.529 .709 & 50.635 .568 & 3.999 .501 & 92.867 .715 & 195.032 .493 \\
\hline
\end{tabular}




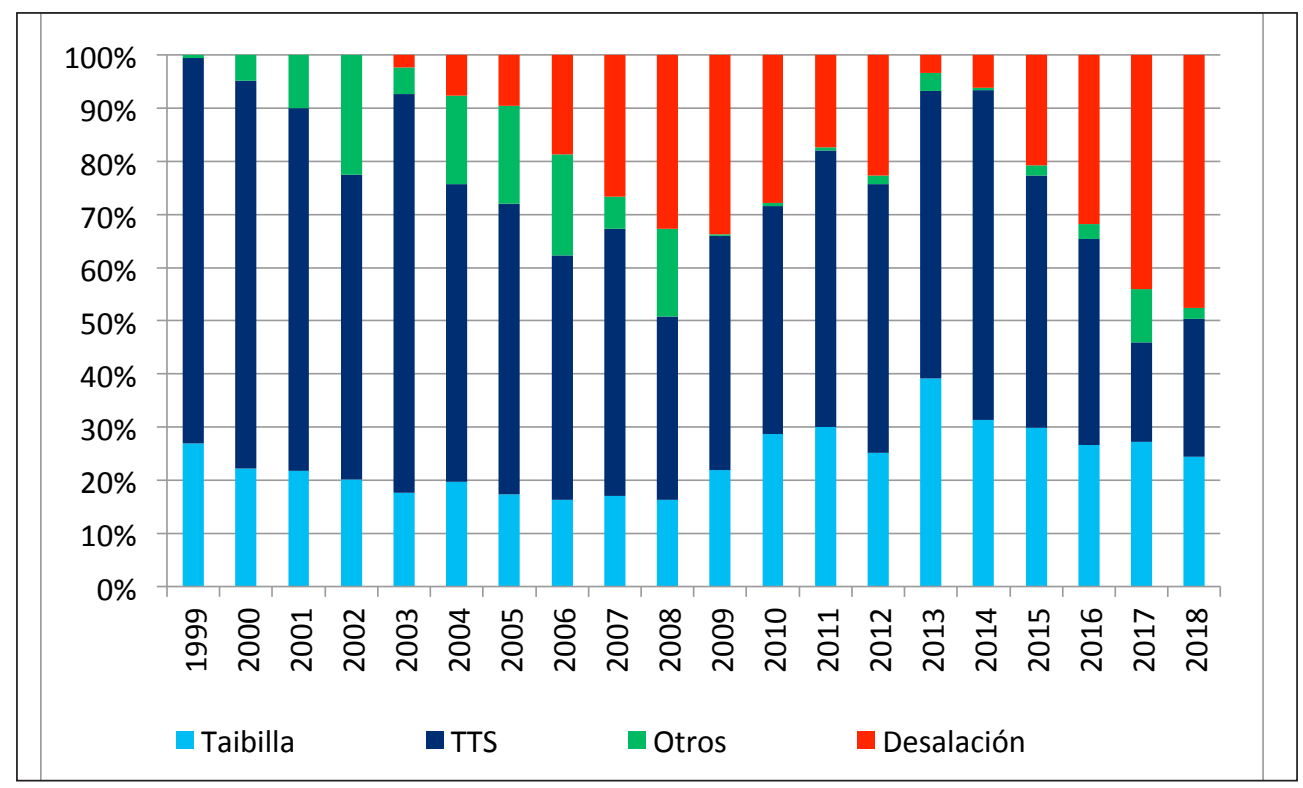

Figura 7. Participación según origen del agua en el "mix hídrico" de MCT (\%). Fuente: elaboración propia a partir de MCT (2019).

A pesar de que la población abastecida ha aumentado por encima de los 2,5 millones de personas, el volumen total distribuido por la MCT ha disminuido en los últimos años debido a las mejoras en las redes de distribución. También las empresas ocupadas en la distribución de agua en baja han conseguido mejorar la eficiencia, mediante las mejoras introducidas en las redes de suministro municipal, con el consiguiente descenso en el consumo per cápita. A modo de ejemplo, en Cartagena la empresa HIDROGEA ha pasado en diez años de un rendimiento del 81,5 \% en 2008 al 88,5 \% en 2017.

Otras medidas: revitalización de prácticas y nuevas técnicas de aumento de recursos y reducción de consumos

Las medidas que se han empleado para la captación de aguas pluviales y su distribución a los espacios regados, han consistido en aprovechar en las explotaciones agrarias aquellos espacios impermeabilizados (cubiertas de invernadero), y el agua que cae entre las calles de los invernaderos, dirigiéndolas a un embalse de acumulación situado aguas abajo. También sucede con viales y calles de núcleos urbanos, como el caso de Puerto Lumbreras, que se dirigen a embalses de comunidades de regantes y a tanques de tormenta para su posterior uso.

La revitalización de técnicas de captación de subálveas, de escorrentías subsuperficiales captadas mediante pozos horizontales (galerías) como sucede en el entorno del Mar Menor por la C.R. Arco 
Sur - Mar Menor. También el esfuerzo de la regeneración de aguas residuales tratadas para reúsos (ambiental, ocio y recreación, regadíos, etc.).

En cuanto a las técnicas empleadas para reducir las demandas, resaltar el caso de las cubiertas de embalses que se está produciendo en la segunda generación de modernización en comunidades de regantes como Huércal-Overa Norte, con cinco embalses cubiertos que sirven para la reducción de evaporación y captación de aguas de lluvia. En el riego de cultivos hortícolas, el empleo de la cinta de riego enterrada evita pérdidas por evaporación en la distribución del agua para riego, etc. Si se cerrase o disminuyese el agua procedente del ATS, habrá que invertir en ahorro de consumo y, en modos de disminuir costes energéticos en la desalación.

El papel de los aljibes se ha recuperado en los últimos años en algunos países. Los sistemas de captación de aguas pluviales en tejados (SCAP) para usos urbanos están presentes en cerca de dos millones de hogares de Australia y, permiten satisfacer el $8 \%$ del uso de agua doméstica en este país (Campisano et al. 2017). Nuestros tradicionales aljibes del medio rural significan un potencial para hacer frente a situaciones de escasez de agua, extendiéndoles incluso a edificios plurifamiliares y a comunidades de vecinos. Ejemplos de esa cultura tradicional es el mantenimiento de un aljibe, alimentado por el tejado a dos aguas de una vivienda de unos $160 \mathrm{~m}^{2}$ de superficie, que abastece a dos familias de agua de boca, aún hoy en una pedanía de Murcia.

\section{CONCLUSIONES y PROPUESTAS}

Las situaciones de sequía meteorológica y sequía hidrológica, e incluso la coincidencia en el tiempo y en el espacio de ambos tipos de sequía, ha obligado a gestionar el agua de forma integral (recursos y demandas). El Plan Especial de Sequía de la Demarcación del Segura propone medidas que apuestan por la diversificación de recursos y la gestión integrada.

La situación se agrava si se suceden varios años con bajas precipitaciones y se genera falta de existencias de agua en los embalses, a lo que a veces se suman también los descensos en las transferencias de agua (tanto en el Tajo - Segura como en el Negratín - Almanzora). En esta situación, la desalinización adquiere más importancia pasando de recurso complementario a estratégico en el ámbito de la política de oferta de recursos. En el caso de los regadíos, se han activado elementos de la política de control de las demandas (técnicas de riego deficitario, variedades de cultivos menos exigentes en agua, segunda generación de modernización, etc.), que ya se van convirtiendo en prácticas y tendencias habituales.

Los modelos de gobernanza y prácticas ante las sequías, justifican la resiliencia y las medidas de adaptación que debieran tomarse ante el calentamiento global y el cambio climático. A estas situaciones de crisis por la falta de agua que afecta al desarrollo regional del Sureste, se responde con medidas y prácticas que se desarrollan paulatinamente según la respuesta a su puesta en práctica. Así es recuperar la oferta de recursos mediante la apertura de pozos de sequía, facilitar los contratos de cesiones temporales de derechos y bancos de agua, ampliar y asegurar los trasvases, aumentar y mejorar la captación de aguas pluviales y subálveas, continuar con la regeneración de residuales y aumentar las concesiones de ellas a los regadíos, innovar en las técnicas de desalinización (reduciendo consumos y costes energé- 
ticos), invertir en las redes de recuperar las aguas regeneradas para llevarlas a los usuarios (caso de los perímetros regables), conectar las plantas desaladoras con otras redes de autovías del agua como las de la MCT, Postrasvase Tajo - Segura y de la propia Cuenca del Segura, etc.

También se actúa sobre las demandas con modernización de regadíos (primera y segunda generación), con renovación de las redes de alta y baja de abastecimientos (más depósitos, mejor material en las conducciones, menos pérdidas, adecuación tarifaria, etc.), desarrollo de técnicas de riego y sistemas de cultivos menos exigentes en agua, con menos pérdidas por evaporación y más eficiencia en el uso del agua en riego (cinta de riego enterrada, solución reciclada de nutrientes New GrowingSystem (NGS), prácticas de riego deficitario, etc.).

El Sureste es un espacio resiliente, donde la sociedad está adaptada a las situaciones de simultaneidad de sequías meteorológicas e hidrológicas, con una amplia infraestructura creada a lo largo del tiempo para conseguir recursos, pero también con una cultura de valoración y saber hacer con ellos, que evoluciona a la par de los avances de investigación y tecnología sin olvidar lo tradicional, que puede mantener o revalorizar. Todo son medidas para reducir la vulnerabilidad.

\section{REFERENCIAS}

Agencia Estatal de Meteorología (AEMET) (2017): Proyecciones climáticas para el siglo XXI. Disponible en: http://aemet.es/es/serviciosclimaticos/cambio climat

Altieri, M. A. \& Nicholls, C. I. (2013): Agroecología y resiliencia al cambio climático: Principios y consideraciones metodológicas. Agroecología, 8 (1), 7-20.

Bruins, H. J. (2012): Ancient desert agriculture in the Negev and climate-zone boundary changes during average, wet and drought years. Journal of Arid Environments, 86, 28-42.

Campisano, A; Butler, D; Ward, S. et al. (2017): Urban rainwater harvesting systems: Research, implementation and future perspectives. Water Research, 115, 195-209.

Centro de Estudios y Experimentación de Obras Públicas (CEDEX) (2013): Informe técnico sobre "Asistencia técnica, investigación y desarrollo tecnológico en materias de competencia de la Dirección General del Agua (2007-2011)". Madrid: Centro de Estudios Hidrográficos. 139 p.

Centro de Estudios y Experimentación de Obras Públicas (CEDEX) (2017): Evaluación del impacto del cambio climático en los recursos hídricos y sequías en España. Ministerio de Agricultura y Pesca, Alimentación y Medio Ambiente. Disponible en: http//cedex.es/CEDEX/LANG CASTELLANO/ ORGANISMO/CENTYLAB/CEH/Documentos Descargas

CHS-SAIHSEGURA (2019): Estudio de precipitaciones brutas registradas en la Cuenca del Segura. Ministerio para la Transición Ecológica. Confederación Hidrográfica del Segura. 11 pp.

Cooley, H.; Donnelly, K.; Phurisamban, R.; Subramanian, M. (2015): Impacts of California's ongoing drought: Agriculture. Oakland: Pacific Institute. ISBN: 978-1-893790-66-7.

Couchoud, S. R. (1965): Hidrología histórica del Segura: secas, riadas, rogativas, calamidades, trabajos y esperanzas. Murcia: Colegio de Ingenieros de Caminos, Canales y Puertos. 
Echegaray, J. D. (1851): Memoria sobre las causas de la sequía de las provincias de Almería y Murcia, y de los medios de atenuar sus efectos, escrita con arreglo al programa del Real Decreto de 30 de marzo de 1850. Madrid: Imprenta del Ministerio de Comercio, Instrucción y Obras Públicas.

Folke, C. (2006): Resilience: The emergence of a perspective for social-ecological systems analyses. Global environmental change, 16 (3), 253-267.

Gil-Guirado, S. (2017): Deconstruyendo riesgos. Cuatro siglos de cambios en la vulnerabilidad y adaptación a las inundaciones y sequías en Murcia. Revista de Historia Moderna, Anales de la Universidad de Alicante, 35, 308-344.

Gil-Guirado, S. \& Pérez-Morales, A. (2019): Variabilidad climática y patrones termopluviométricos en Murcia (1863-2017): Técnicas de análisis climático en un contexto de cambio global. Investigaciones Geográficas, 71, 27-54.

Gil Meseguer, E. (2014): El Sureste peninsular. Rasgos de un medio semiárido como el de Pulpí y su entorno. El dinamismo del regadío de Pulpí. Murcia. C.R. de Pulpí. Pp. 49-72.

Gil-Meseguer, E.; Bernabé-Crespo, M. B.\& Gómez-Espín, J. Ma (2017): Las políticas de trasvases de agua y desalación en España, sus repercusiones en la ordenación del territorio del Sureste. XXV Congreso de la AGE, Naturaleza, territorio y ciudad en un mundo global, 2480-2489. Madrid.

Gil-Meseguer, E.; Bernabé-Crespo, M. B.\& Gómez-Espín, J. Mª (2019a): Resiliencia ante las sequías en el Sureste de España: respuestas de abastecimientos y regadíos. En: Actas del XXVI Congreso de la Asociación Española de Geografía "Crisis y espacios de oportunidad. Retos para la Geografía", 549-566. Valencia, 22-25 octubre de 2019. AGE y Universidad de Valencia.

Gil-Meseguer, E., Bernabé-Crespo, M. B. \& Gómez-Espín, J. Mª (2019b): Recycled sewage - A water resource for dry regions of Southeastern Spain. Water Resources Management 33 (2), 725-737. DOI: 10.1007/s11269-018-2136-9

Gil-Meseguer, E. \& Gómez-Espín, J. Ma (2015): Cambios en la ordenación territorial del Bajo Almanzora auspiciados por los trasvases Tajo - Segura y Negratín - Almanzora. En: De la Riva, J.; Ibarra, P.; Montorio, R.; Rodrigues, M. (Eds.): Análisis espacial y representación geográfica: innovación y aplicación, 139-147. Universidad de Zaragoza-AGE. ISBN: 978-84-92522-95-8.

Gil-Olcina, A.\& Rico-Amorós, A. M. (2018): Canal Bajo del Algar. Columna vertebral de la Marina Baja. Instituto Universitario de Geografía. Comunidad de Regantes Canal Bajo del Algar. 502 p.

Gómez, J. Mª; López, J.A.\& Montaner, E. (2011): Modernización de regadíos: sostenibilidad social y económica. La singularidad de los regadíos del Trasvase Tajo - Segura. SCRATS, f. Séneca, EDITUM. 439 p.

Gómez-Limón, J. A.\& Guerrero-Baena, M. D. (2019): Diseño de un seguro indexado para la cobertura del riesgo de sequía hidrológica en la agricultura de regadío. Agua y Territorio, 13, 79-92.

Holling, C. S. (1973): Resilience and stability of ecological systems. Annual Review of Ecology and Systematics, 4 (1), 1-23.

Iglesias, A.; Garrote, L.; Cancelliere, A.; Cubillo, F.; Wilhite, D. (2009): Coping with drought risk in agriculture and water supply systems. Ed: Springer. ISBN: 978-1-4020-9044-8. 
Kirby, M.; Bark, R.; Connor, J.; Qureshi, M. E.; Keyworth, S. (2014): Sustainable irrigation: How did irrigated agriculture in Australia's Murray-Darling Basin adapt in the Millennium Drought? Agricultural Water Management, 145, 154-162.

Lal, R.; Delgado, J. A.; Gulliford, J.; Nielsen, D.; Rice, C. W.; Van Pelt, R. S. (2012): Adapting agriculture to drought and extreme events. Journal of Soil and Water Conservation, 67 (6), 162A-166A.

Lloret, F. (2012): Vulnerabilidad y resiliencia de ecosistemas forestales frente a episodios extremos de sequía. Ecosistemas 21 (3), 85-90. Doi.:10.7818/ECOS.2012.21-3.11

López, J. A.; Gómez, J. Ma \& Gil, E. (2017): Concentración parcelaria, puesta en riego y desarrollo rural: el caso de Yéchar (Mula-Región de Murcia): De 1973 a 2016. Investigaciones Geográficas, 67, 173-192.

Morote, A. F. (2018): La desalinización. De recurso cuestionado a recurso necesario y estratégico durante situaciones de sequía para los abastecimientos en la Demarcación Hidrográfica del Segura. Investigaciones Geográficas, 70, 47-69

Nicholls, C. I. \& Altieri, M. A. (2011): Modelos ecológicos y resilientes de producción agrícola para el siglo XXI. Agroecología, 6, 28-37.

O'Brien, M. J. \& Holland, T. D. (1992): The role of adaptation in archaeological explanation. American Antiquity, 57 (1), 36-69.

Olcina, J. (2001): Tipología de sequías en España. Ería, 56, 201-227.

Ortega-Reig, M.; García-Mollá, M.; Sanchis-Ibor, C.; Pulido-Velázquez, M.; Girard, C.; Marcos, P.; Ruiz-Rodríguez, M.\& García-Prats, A. (2018): Adaptación de la agricultura a escenarios de cambio global. Aplicación de métodos participativos en la Cuenca del río Júcar (España): Economía Agraria y Recursos Naturales, 18 (2), 29-51.

Pereira, L.S. \& Paulo, A. A: (2004): Droughts: concepts, indices and prediction. En: Hamdy (Ed.): Water Management for Drought Mitigation in the Mediterranean. 2nd Regional Conference on Arab Water, Cairo, April 12-16. Egypt National Water Resources Center CIHEAM-IAMB, 103-132.

Rico, A. M.; Saurí, D.; Olcina-Cantos, J. y Vera-Rebollo, J. F. (2013): Beyond megaprojects? Water alternatives for mass tourism in coastal Mediterranean Spain. Water Resources Management, Vol. 27, Issue 2, 553-565.

Sanchis, C. \& Boelens, R. (2018): Gobernanza del agua y territorios hidrosociales: del análisis institucional a la ecología política. Cuadernos de Geografía, 101, 13-28.

Sanchis-Ibor, C.; Boelens, R. \& García-Mollá, M. (2017): Collective irrigation reloaded. Re-collection and re-moralization of water management after privatization in Spain. Geoforum, 87, 38-47.

Sanchis-Ibor, C.; García-Mollá, M.; Torregrosa, T.; Ortega-Reig, M. \& Sevilla, M. (2019): Water transfers between agricultural and urban users in the region of Valencia (Spain): A case of weak governance? Water Security, 7, 100030.

Verhagen J.; Put M.;Zaal F; van Keulen H. (2004): Climate Change and Drought Risks for Agriculture. In: Dietz A.J., Ruben R., Verhagen A. (eds): The Impact of Climate Change on Drylands. Environment Eु Policy, vol 39. Springer, Dordrecht. ISBN: 978-1-4020-1952-4. https://doi.org/10.1007/14020-2158-5_6. 
Cómo citar este artículo:

Gil-Meseguer, E., Bernabé-Crespo, M. B., Gómez-Espín, J. M. (2020). Resiliencia en el consumo de agua por parte de abastecimientos y regadíos ante las sequías en el Sureste de España. Cuadernos de Geografía, 104, 107-130. https://doi.org/10.7203/cguv.104.16328

\section{(c) $(1)(\Theta) \Theta$}

Este obra está bajo una licencia de Creative Commons Reconocimiento-NoComercial-SinObraDerivada 4.0 Internacional. 